Supplement of Geosci. Model Dev., 14, 3361-3382, 2021

https://doi.org/10.5194/gmd-14-3361-2021-supplement

(C) Author(s) 2021. CC BY 4.0 License.

(c) (i)

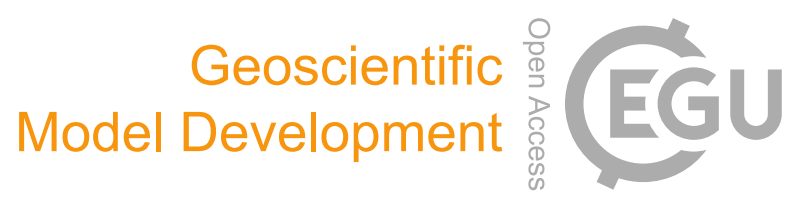

Supplement of

\title{
Addressing biases in Arctic-boreal carbon cycling in the Community Land Model Version 5
}

\section{Leah Birch et al.}

Correspondence to: Leah Birch (lbirch@woodwellclimate.org, birch.leah@gmail.com) and Brendan M. Rogers (brogers@woodwellclimate.org)

The copyright of individual parts of the supplement might differ from the article licence. 
Table S1. List of Eddy Covariance Towers used in model development and validation of model improvements.

\begin{tabular}{|c|c|c|c|c|c|}
\hline EC Tower Name & Latitude & Longitude & PFT & Reference & Source \\
\hline \multicolumn{6}{|l|}{ Development } \\
\hline US-EML & $63.8784^{\circ} \mathrm{N}$ & $-149.2536^{\circ} \mathrm{W}$ & Shrub/Grass & Belshe et al. (2012) & http://ameriflux.lbl.gov/sites/siteinfo/US-EML \\
\hline CA-OAS & $53.62889^{\circ} \mathrm{N}$ & $-106.19779^{\circ} \mathrm{W}$ & BDT & Black (2016) & http://sites.fluxdata.org/CA-Oas/ \\
\hline CA-QC2 & $49.7598^{\circ} \mathrm{N}$ & $-74.5711^{\circ} \mathrm{W}$ & NET/BDT & Margolis (2018) & http://ameriflux.lbl.gov/sites/siteinfo/CA-Qc2 \\
\hline RU-SKP & $62.2550^{\circ} \mathrm{N}$ & $129.1680^{\circ} \mathrm{E}$ & NDT & Maximov (2016) & http://sites.fluxdata.org/RU-SkP/ \\
\hline \multicolumn{6}{|l|}{ Towers Witheld } \\
\hline US-ATQ & $70.4696^{\circ} \mathrm{N}$ & $-157.40896^{\circ} \mathrm{W}$ & Shrub/Grass & Oechel et al. (2014) & http://sites.fluxdata.org/US-Atq/ \\
\hline CA-NS1 & $55.87917^{\circ} \mathrm{N}$ & $-98.48389^{\circ} \mathrm{W}$ & NET & Goulden (2016b) & http://sites.fluxdata.org/CA-NS1/ \\
\hline CA-NS6 & $55.91667^{\circ} \mathrm{N}$ & $-98.96444^{\circ} \mathrm{W}$ & Shrubs & Goulden (2016a) & http://sites.fluxdata.org/CA-NS6/ \\
\hline CA-NS7 & $55.63583^{\circ} \mathrm{N}$ & $-99.94833^{\circ} \mathrm{W}$ & Shrubs & Goulden (2016a) & http://sites.fluxdata.org/CA-NS7/ \\
\hline CA-SF1 & $54.4850300^{\circ} \mathrm{N}$ & $-105.81757^{\circ} \mathrm{W}$ & NET & Amiro (2016) & http://sites.fluxdata.org/CA-SF1/ \\
\hline CA-QFO & $49.6925^{\circ} \mathrm{N}$ & $-74.34206^{\circ} \mathrm{W}$ & NET & Margolis (2016) & http://sites.fluxdata.org/CA-Qfo/ \\
\hline CA-GRO & $48.2167^{\circ} \mathrm{N}$ & $-82.1556^{\circ} \mathrm{W}$ & NET & McCaughey (2016) & http://sites.fluxdata.org/CA-Gro/ \\
\hline RU-SAM & $72.3738^{\circ} \mathrm{N}$ & $126.4958^{\circ} \mathrm{E}$ & Grass & Kutzbach et al. (2002-2014) & http://sites.fluxdata.org/RU-Sam/ \\
\hline RU-TKS & $71.59427^{\circ} \mathrm{N}$ & $128.88782^{\circ} \mathrm{E}$ & Grass & Aurela (2016) & http://sites.fluxdata.org/RU-Tks/ \\
\hline RU-COK & $70.82914^{\circ} \mathrm{N}$ & $147.49428^{\circ} \mathrm{E}$ & Shrub & Dolman et al. (2016) & http://sites.fluxdata.org/RU-Cok/ \\
\hline FI-SOD & $67.36239^{\circ} \mathrm{N}$ & $26.63859^{\circ} \mathrm{E}$ & NET & Aurela et al. (2016) & http://sites.fluxdata.org/FI-Sod/ \\
\hline
\end{tabular}

\section{S2 Model Development Supporting Information}

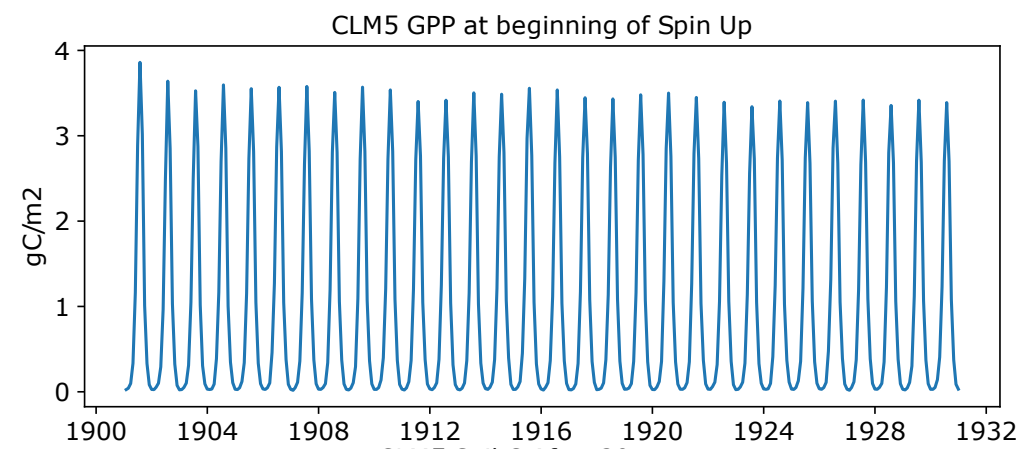

Figure S1. CLM5.0 Output During Spin-Up of Model Development. We see an initial spike in GPP at the start of the simulation. Within 20 years, the variability is due to climate forcing from cycling the years 1901 to 1920. 

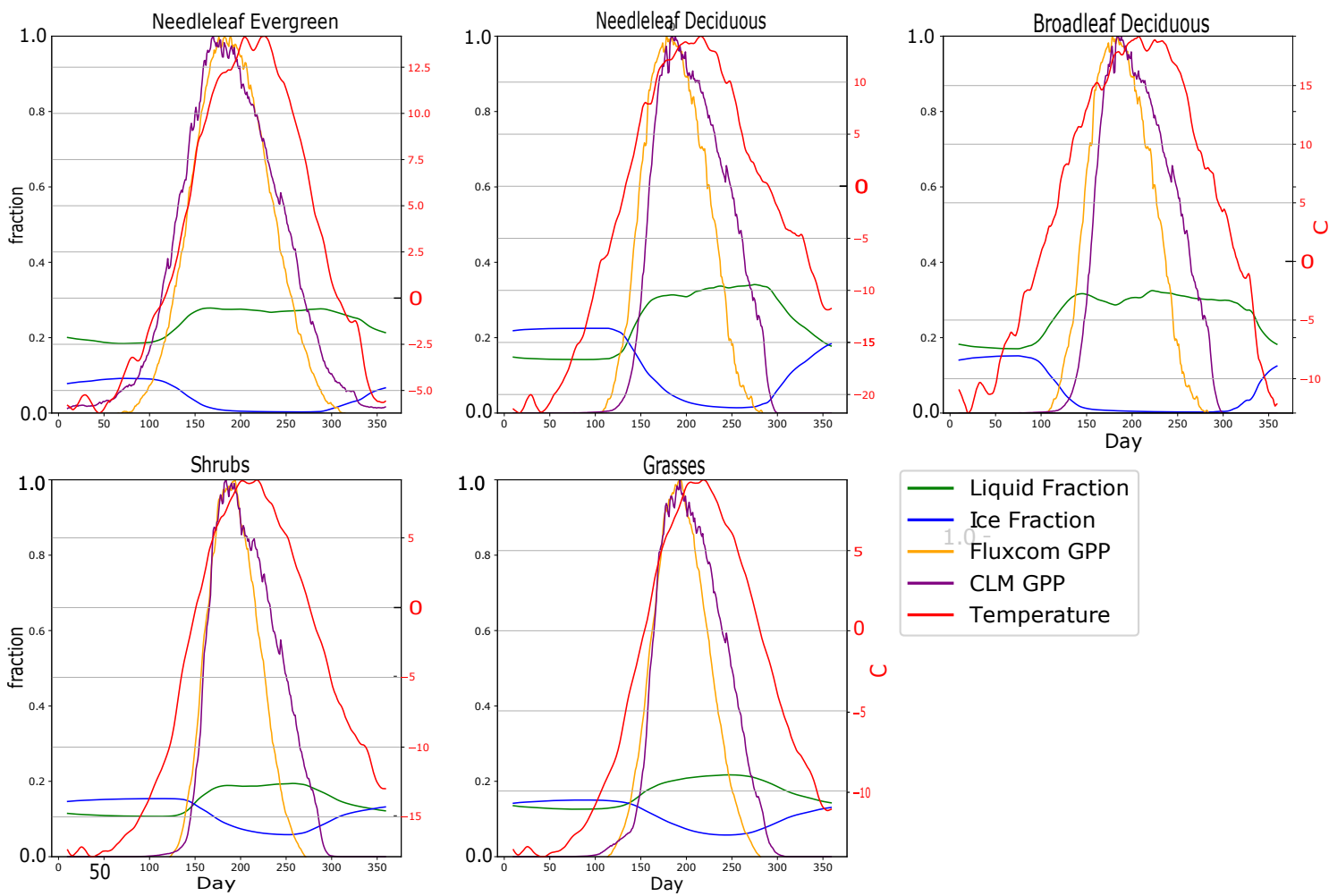

Figure S2. The timing of daily GPP throughout the year in FluxCom and CLM compared to 3rd layer soil temperature, soil ice and soil water. Panels are contain yearly time series sorted by each PFT and latitude band. GPP and soil water/ice have been scaled to be fractional, since timing of photosynthesis was the focus of this analysis.

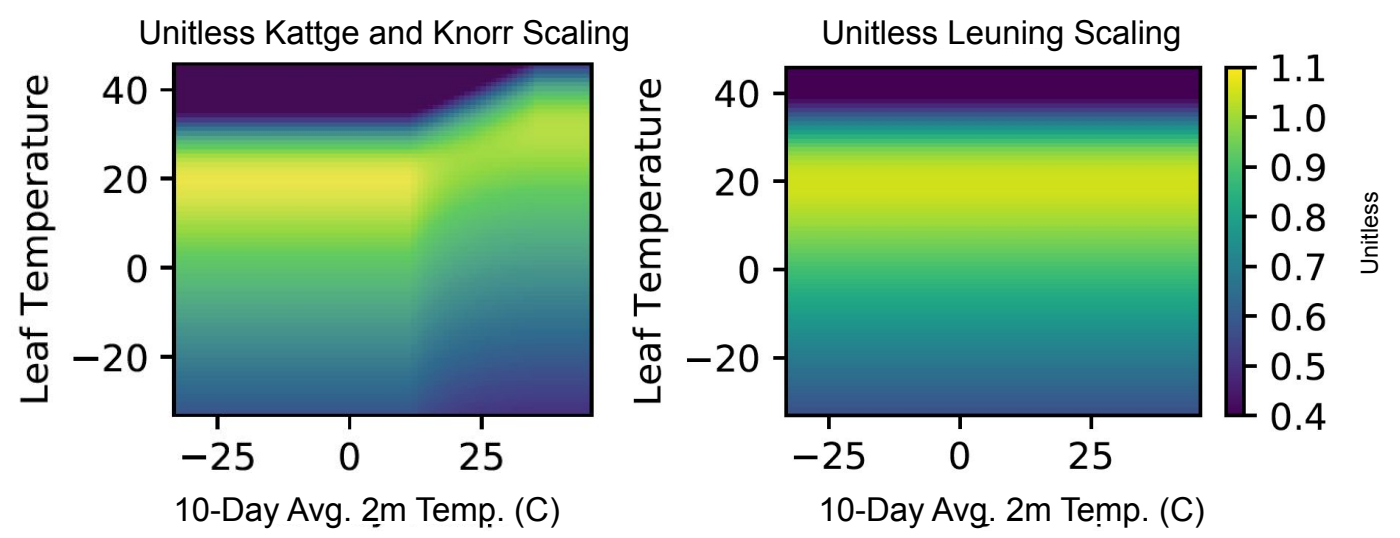

Figure S3. The temperature acclimation scaling for Kattge and Knorr (2007) (left) Below $11^{\circ} \mathrm{C}, \mathrm{J}_{\max }$ and $\mathrm{V}_{c \max }$ are scaled high with this unitless values with a visible discontinuity going to warmer temperatures. In the parameterization from Leuning (2002) (right), the maximum scale value is decreased and contains no discontinuity. 
Table S2. Model Development Effects on maximum summer GPP compared to CLM5.0 release by PFT. The model names represent the type of model improvement and correspond to the list of model improvements in Section 3.3. For example, "Onset" indicates that improvements were made to the phenology onset scheme. Each model development listed builds on the the simulation before it. $\downarrow$ signifies a $<25 \%$ change in model simulation. $\Downarrow$ signifies a $>25 \%$ change in model simulation.

\begin{tabular}{lccccc}
\hline \hline Model Dev. Name & NET & NDT & BDT & Shrubs & Grass \\
\hline 1. Onset & - & $\uparrow$ & $\uparrow$ & $\uparrow$ & $\uparrow$ \\
2. Offset & - & $\downarrow$ & $\downarrow$ & $\downarrow$ & $\downarrow$ \\
3. Maximum day & $\downarrow$ & $\downarrow$ & $\downarrow$ & $\downarrow$ & $\Downarrow$ \\
4. Leuning Scaling & $\downarrow$ & $\downarrow$ & $\downarrow$ & $\downarrow$ & $\downarrow$ \\
5. Predictive Spring J max $_{\text {max }} / V_{\text {cmax }}$ & - & $\uparrow$ & $\uparrow$ & $\downarrow$ & $\downarrow$ \\
6. Dynamic Stem Leaf Ratio & - & $\uparrow$ & $\uparrow$ & $\downarrow$ & - \\
7/8. Realistic Root-Leaf Ratio & - & $\uparrow$ & $\uparrow$ & $\Downarrow$ & $\Downarrow$ \\
\hline All Development & $\downarrow$ & $\uparrow$ & $\uparrow$ & $\Downarrow$ & $\Downarrow$ \\
\hline \hline
\end{tabular}




\section{S3 Night-time Temperature Scaling}

We also find that there is a bug in the computation of the 10-day leaf temperature, where the day time temperature was double counted in Equation 1, and we corrected it to have both $T_{\text {daytime }}$ and $T_{\text {nighttime }}$ included.

$T_{\text {leaf }, 10 \text { day }}=\frac{\text { daylength } * T_{\text {daytime }}+(86400-\text { daylength }) * T_{\text {nighttime }}}{86400}$

We find that correcting this 10-day leaf temperature calculation, generally increases productivity in CLM5.0 PFTs in the Arctic, but by less than $0.5 \mathrm{gC} / \mathrm{m}^{2}$. $T_{\text {leaf,10day }}$ is used to calculate the maximum daily change in $\mathrm{J}_{\max }$ and $\mathrm{V}_{\text {cmax }}$ by calculating the enzyme turnover rate at a particular temperature. Colder temperatures allow $\mathrm{J}_{\max }$ and $\mathrm{V}_{\text {cmax }}$ to change less each time step, and as we noted previously, the default winter predictions are high for the Arctic. Thus, without our modification of average $\mathrm{J}_{\max }$ and $\mathrm{V}_{\text {cmax }}$ in winter, this bug fix would increase the high productivity bias.

\section{S4 Improvements to LUNA}

The LUNA equations and procedure are described below:

$$
J_{\text {max }, t}= \begin{cases}50, & \text { during winter } \\ J_{\text {max }, t-1}+\min \left[\operatorname{mxcon}, J_{\text {max }, \text { opt }}-J_{\text {max }, t-1}\right] \times J_{\text {max }, \text { opt }}, & \text { in growing season, if } J_{\text {max }, \text { opt }} \geq J_{\text {max }, t-1} \\ J_{\text {max }, t-1}+\max \left[-\operatorname{mxcon}, J_{\text {max }, \text { opt }}-J_{\text {max }, t-1}\right] \times J_{\text {max }, \text { opt }}, & \text { in growing season, if } J_{\text {max }, \text { opt }}<J_{\text {max }, t-1}\end{cases}
$$

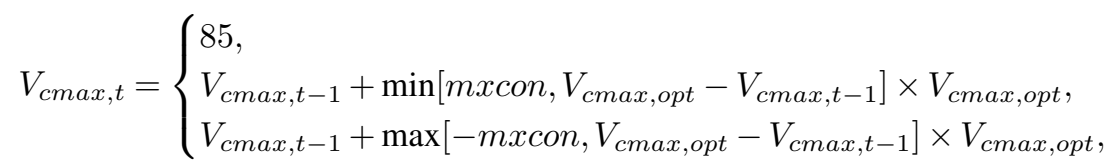

\section{during winter}

in growing season, if $V_{c m a x, o p t} \geq V_{c m a x, t-1}$ in growing season, if $V_{\text {cmax }, \text { opt }}<V_{\text {cmax }, t-1}$

$\mathbf{J}_{\text {max }, \text { opt }}\left(\mathrm{V}_{\text {cmax,opt }}\right)$ is predicted by LUNA as the optimal $\mathbf{J}_{\text {max }}\left(\mathrm{V}_{c \max , \text { opt }}\right)$ for the plant, which as the name states is optimal and does not account for limitations on enzyme resources. The maximum change constraint (mxcon) limits the amount of change for $\mathrm{J}_{\max }$ (and $\mathrm{V}_{\text {cmax }}$ ) based on the resources available to that plant, which can change every time step. This scheme allows $\mathrm{J}_{\max }$ and $\mathrm{V}_{\text {cmax }}$ and thus photosynthesis to be co-limited by resources. We find the change constraint to be a reasonable one to place on $\mathrm{J}_{\max }$ and $\mathrm{V}_{\text {cmax }}$, as it allows for the climatic history on the grid cell to influence the future prediction of leaf photosynthetic traits. However, this scheme for $\mathrm{J}_{\max }$ and $\mathrm{V}_{\text {cmax }}$ is only active during the growing season. In winter when $\mathrm{LAI}=0$ and plants are dormant, $\mathrm{J}_{\max }$ and $\mathrm{V}_{\text {cmax }}$ are not predicted by LUNA and instead are given a default global place holder value. Thus, at the start of the growing season (or first day of spring), $\mathrm{J}_{\max , t}$ and $\mathrm{V}_{c \max , t}$ are directly calculated from the last day of winter:

$$
\begin{aligned}
J_{\max , \text { last day of winter }} & =J_{\max , t-1}=50 \\
V_{c \max , \text { last day of winter }} & =V_{c \max , t-1}=85
\end{aligned}
$$

We find that this global default winter value strongly influences the prediction of $\mathbf{J}_{\max }$ and $\mathrm{V}_{c \max }$ throughout the entire growing season (Supplement Fig. S4). In all of the ABZ PFTs, raising these default values increases mean growing season GPP, whereas decreasing them lowers GPP (Supplement Fig. S4). Furthermore, the constant winter values in Equation 3 represent a high bias globally in $\mathrm{V}_{\text {cmax }}($ ?), contributing additional bias. Due to the sensitivity of this choice and in an effort to leverage the physiological history of a given location, we choose to save the average predictions of $\mathrm{J}_{\max }$ and $\mathrm{V}_{\text {cmax }}$ from the previous growing season for all PFTs $\left(\mathbf{J}_{\text {max,prevyr }}\right.$ and $\left.\mathrm{V}_{\text {cmax,prevyr }}\right)$. We use these pft specific values to initialize $\mathbf{J}_{\max }$ and $\mathrm{V}_{\text {cmax }}$, such that on the first day of the growing season,

$$
\begin{aligned}
J_{\text {max }, p f t, \text { last day of winter }} & =J_{\text {max }, p f t, p r e v y r} \\
V_{c m a x}, p f t, \text { last day of winter } & =V_{c m a x}, p f t, p r e v y r
\end{aligned}
$$


Then Equations 2 and 3 continue the calculation $\mathrm{J}_{\max }$ and $\mathrm{V}_{\operatorname{cmax}}$ for the rest of the growing season. 

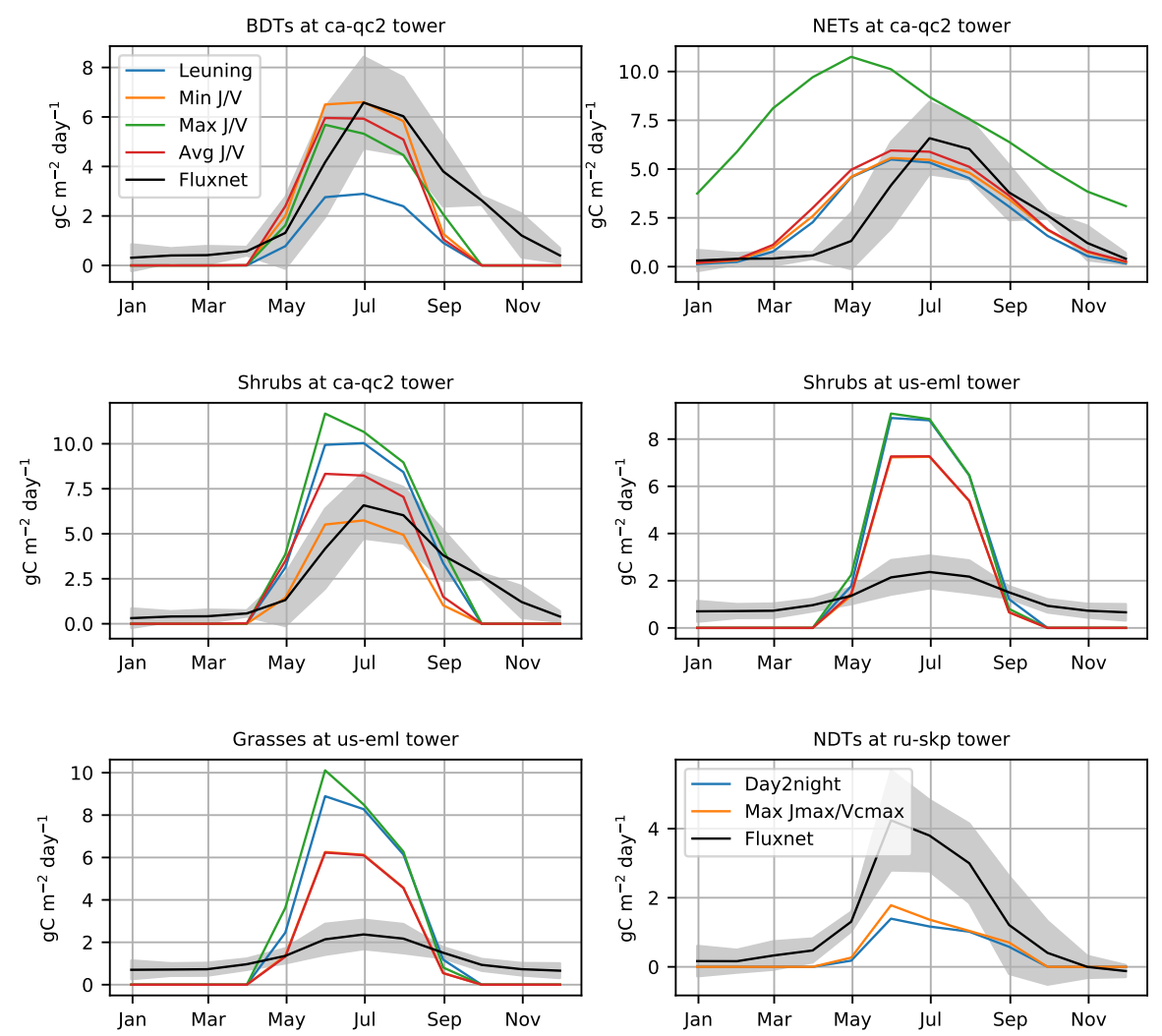

Figure S4. GPP from Intermediate Model Development Steps at Flux Towers for initializing $\mathbf{J}_{\max }$ and $\mathrm{V}_{c \max }$ in spring. Sensitivity test involved increasing the default value (max test in orange) and decreasing the default value (min. test in green) compared to simulations incorporating on the daylight and Leuning scaling changes (blue). The red line depicts the model recommendation choice from the main paper text, where $\mathrm{J}_{\max }$ and $\mathrm{V}_{\text {cmax }}$ are initialized on the average values from the previous year. The GPP measured (black) at specific flux towers is included for comparison. Bottom right panel only includes a point test of increasing the default spring value (orange) 

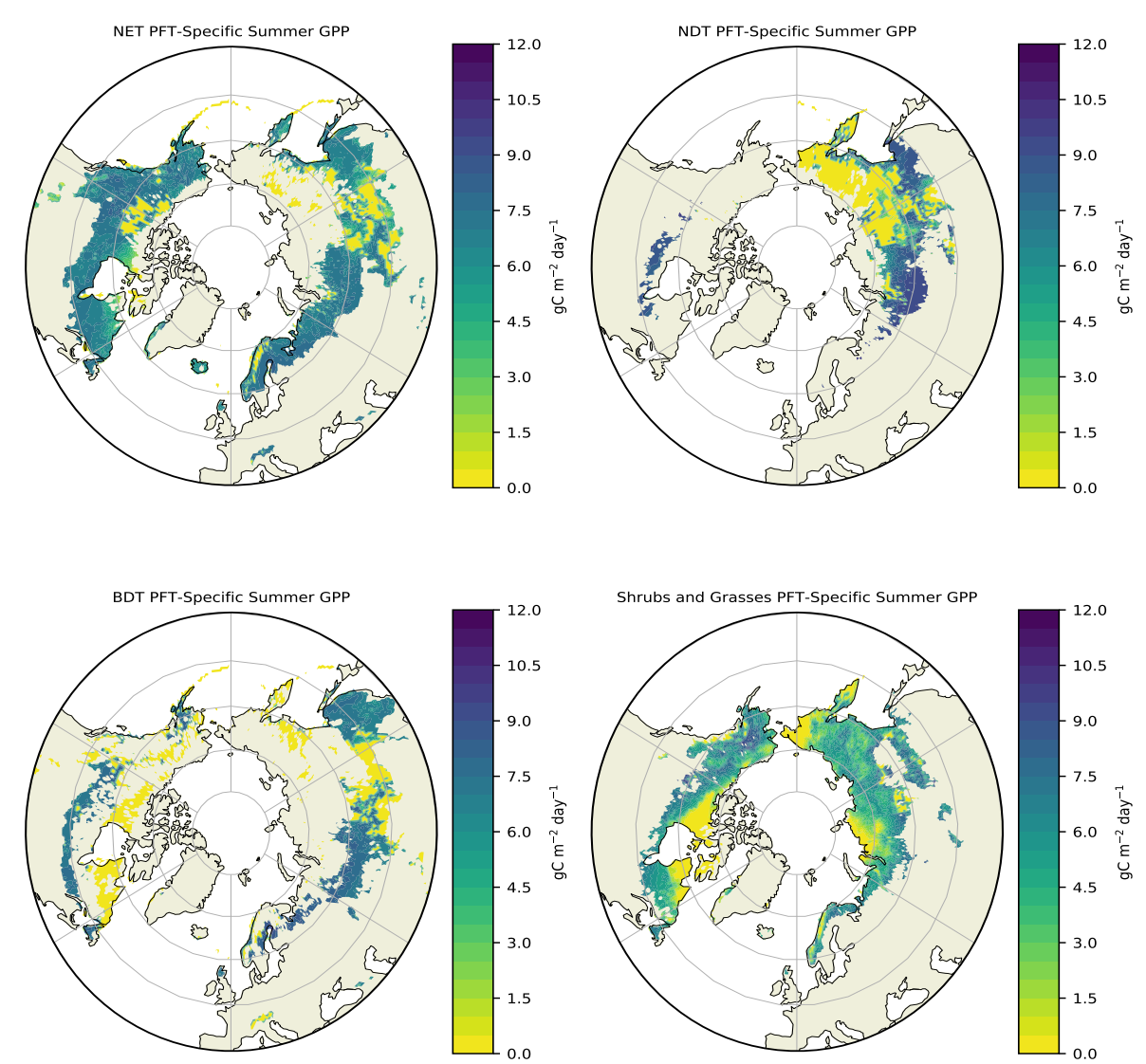

Figure S5. Summer GPP in our model recommendation for PFT specific output. Note large areas of GPP=0 in the top right panel for NDT indicating the "dead zones" in CLM5.0 where we were not successful in bringing alive again systematically. NET, BDT, shrubs and grasses also contain "dead zones", but not in as critical of an area as the larch forest of Siberia. 


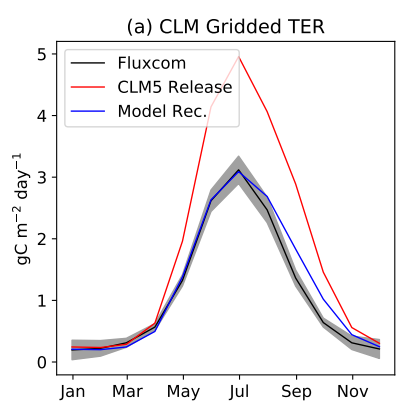

(d) BDT TER

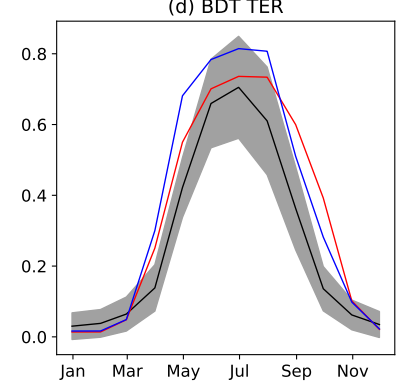

(b) NET TER

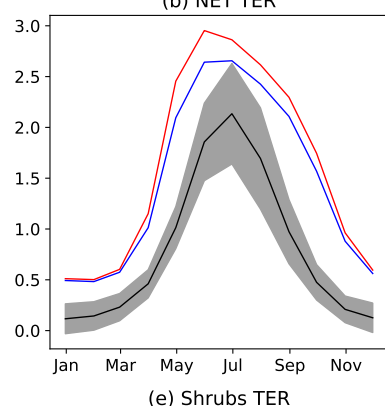

(e) Shrubs TER

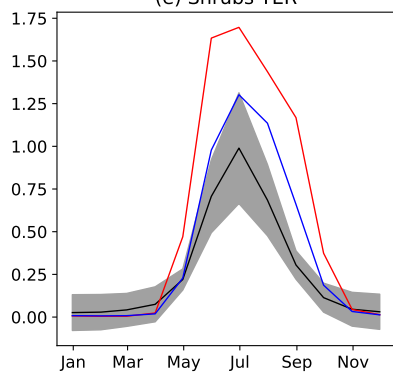

(c) NDT TER
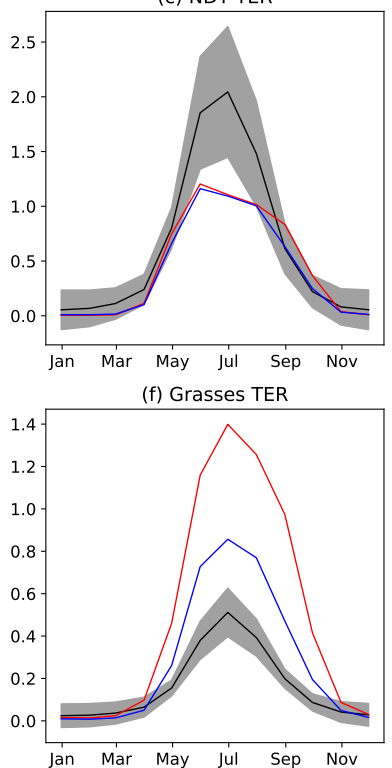

Figure S6. Seasonal TER for gridded CLM output and PFT Specific Output. Comparing CLM Release (red) to our Model Recommendation (blue) to FluxCom (black).
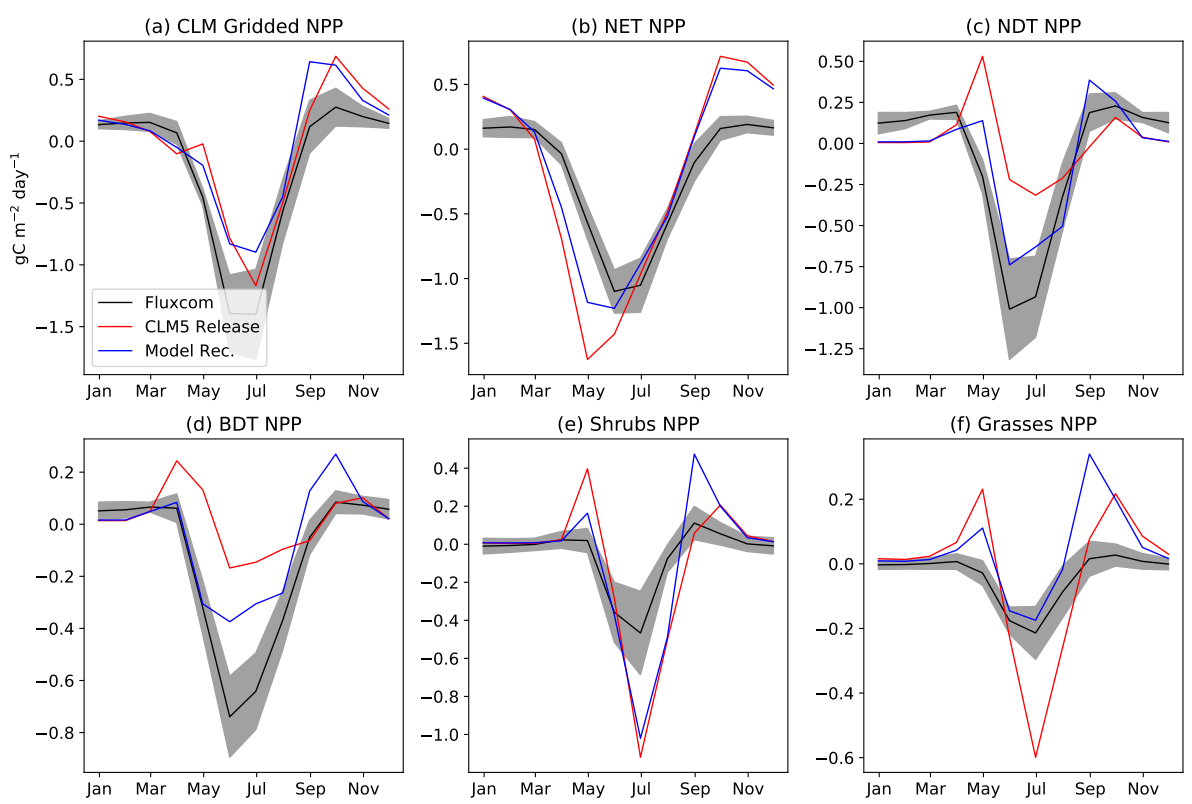

Figure S7. Seasonal NEE for gridded CLM output and PFT Specific Output. Comparing CLM Release (red) to our Model Recommendation (blue) to FluxCom (black). 

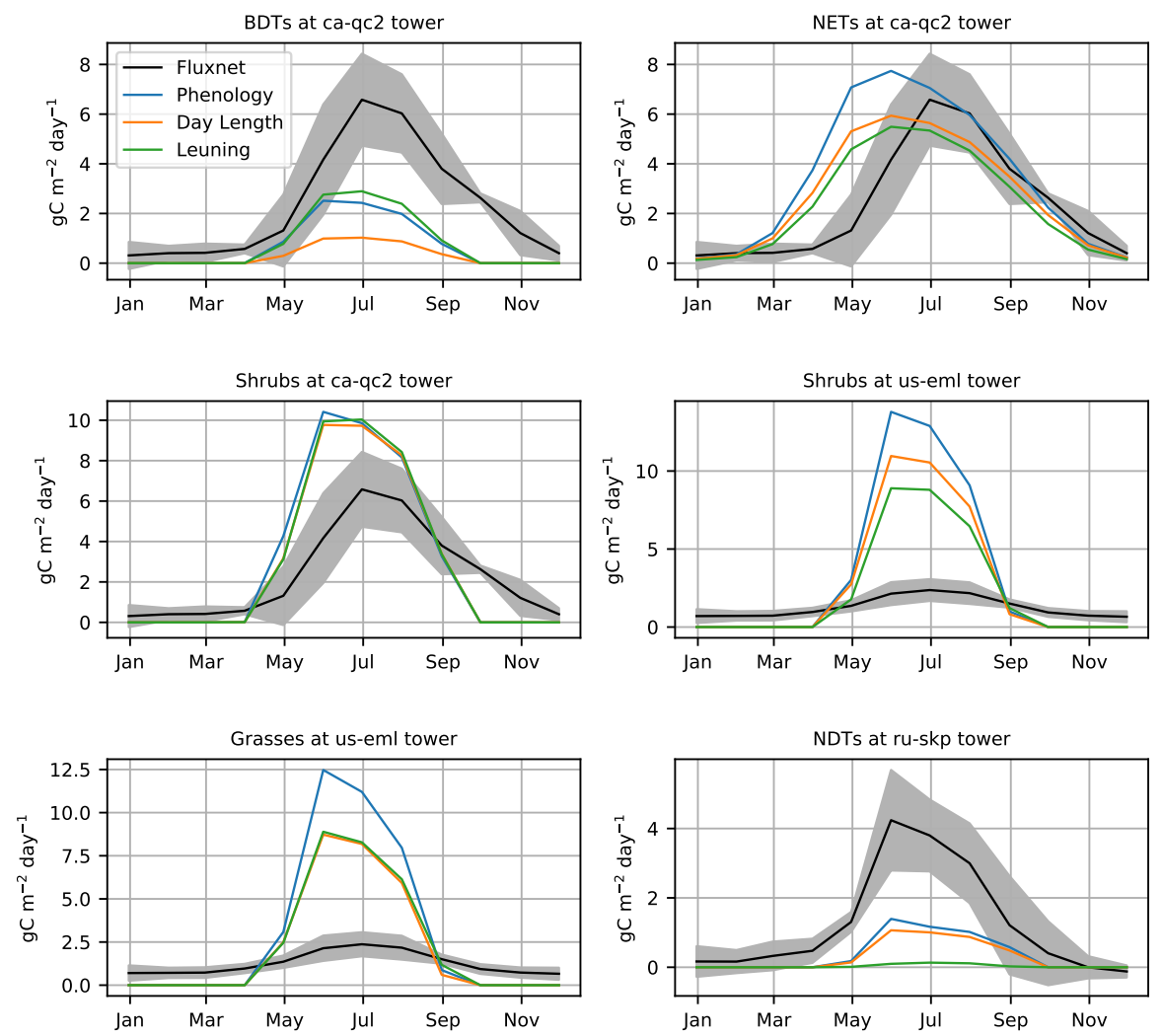

Figure S8. GPP from Intermediate Model Development Steps at Flux Towers for scaling $\mathbf{J}_{\max }$ and $\mathrm{V}_{\text {cmax }}$ using daylight (orange) and Leuning (green) compared to simulations incorporating on the phenology changes (blue). The GPP measured (black) at specific flux towers is included for comparison. 

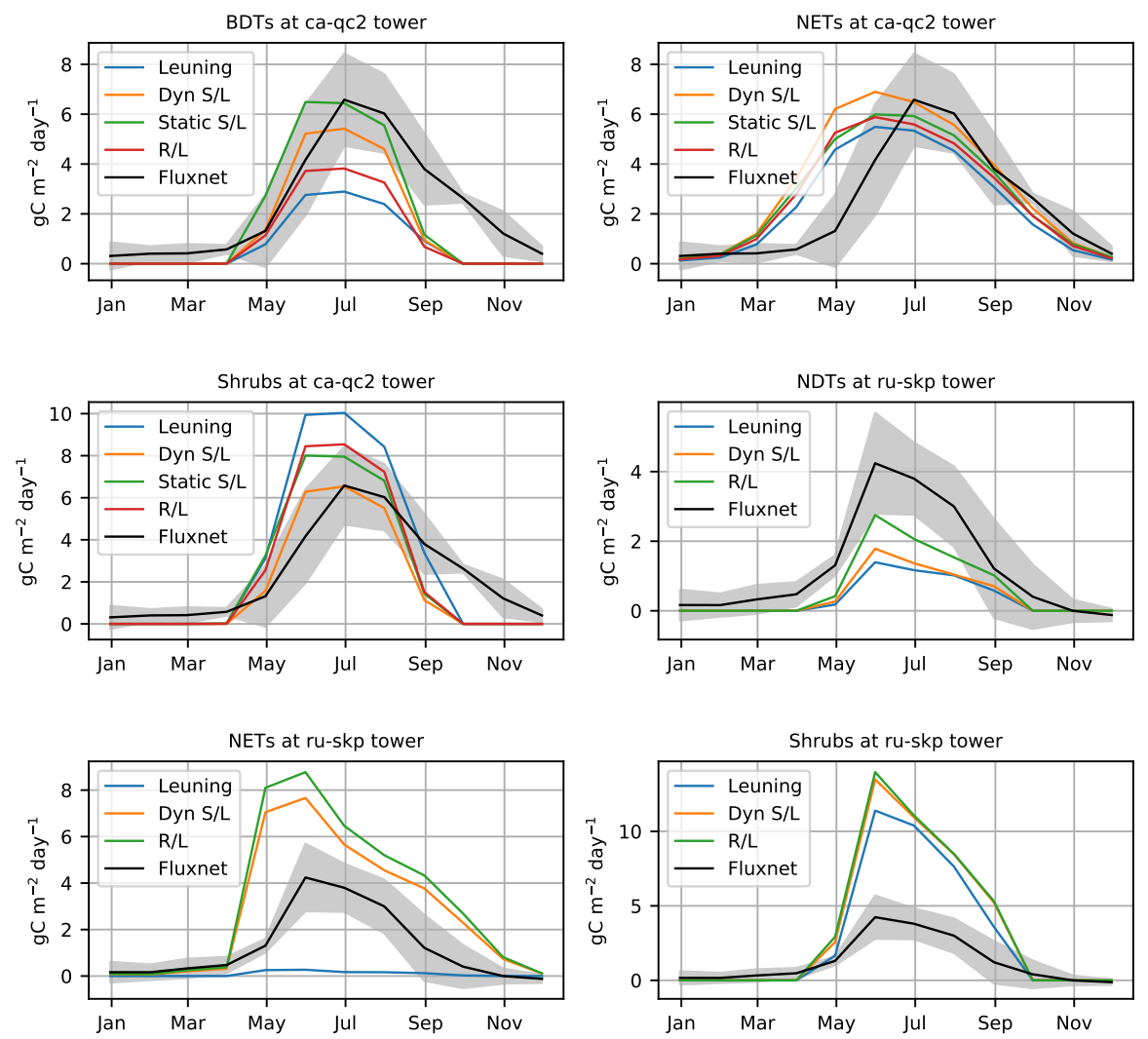

Figure S9. GPP from Intermediate Model Development Steps at Flux Towers for carbon allocation parameters. Dynamic Stem Leaf generally improves the GPP simulation (orange). Sensitivity tests are done using a static value (green) for stem-leaf allocation, but static values here were not clearly supported by observations and did not improve the simulation of shrubs. Observationally based values for root-leaf allocation $(\mathrm{R} / \mathrm{L}=$ red,green) generally increase productivity at these points. Comparisons are done against previous model development step incorporating the Leuning scheme (blue). The GPP measured (black) at specific flux towers is also included for comparison. 

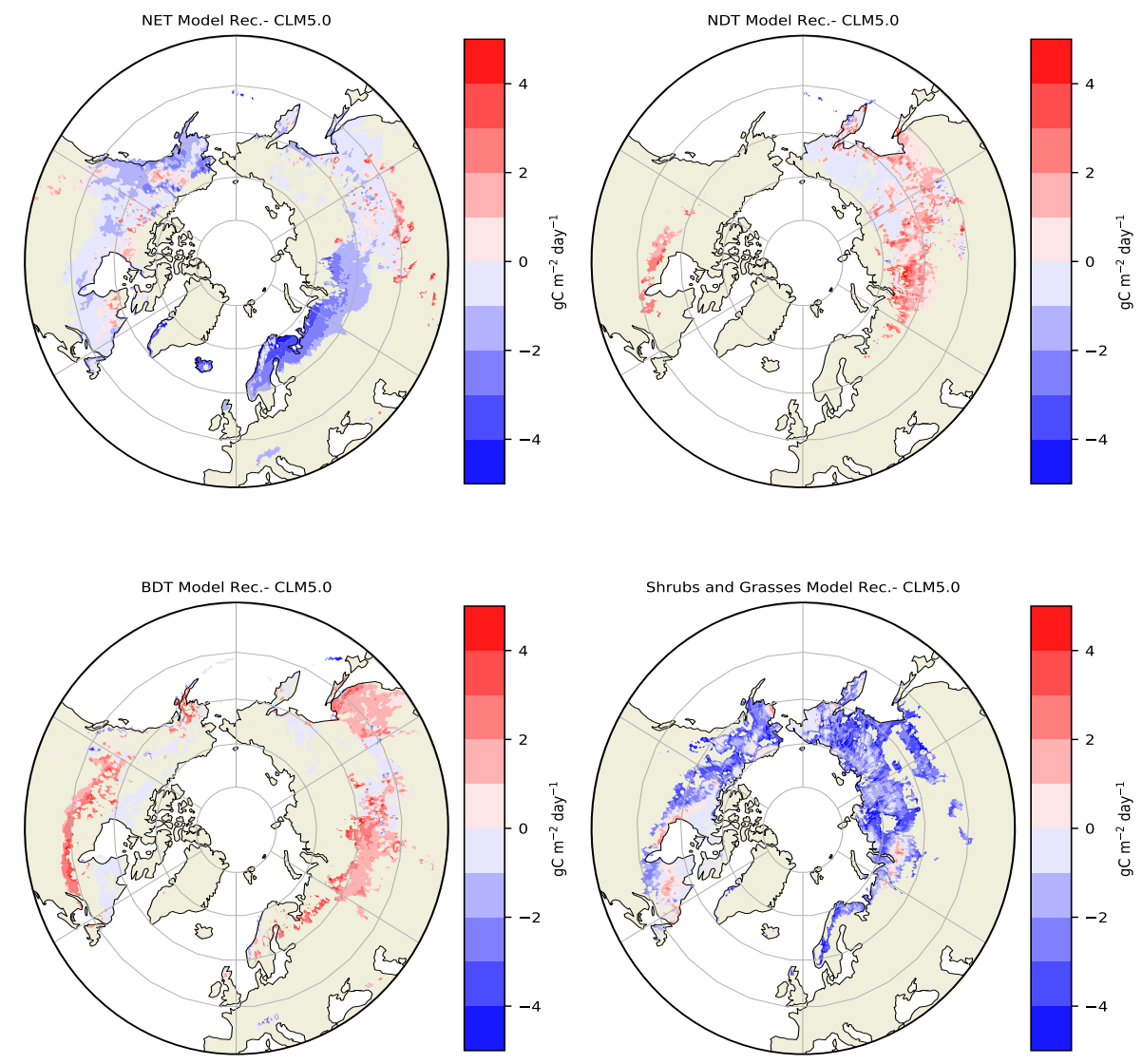

Figure S10. PFT Specific Summer GPP difference between CLM5.0 release and Model Rec. (ModelRec.-CLM5.0). Starting in the top left panel and going left to right, we lower the productivity of NETs across most of the ABZ. NDTs increase in productivity, except where GPP=0 in the CLM5.0 release. We did not increase the number of non-productive NDTs grid cells. BDTs also increased in productivity during the summer in line with observations. We lowered the productivity of grasses and shrubs in the tundra substantially. 

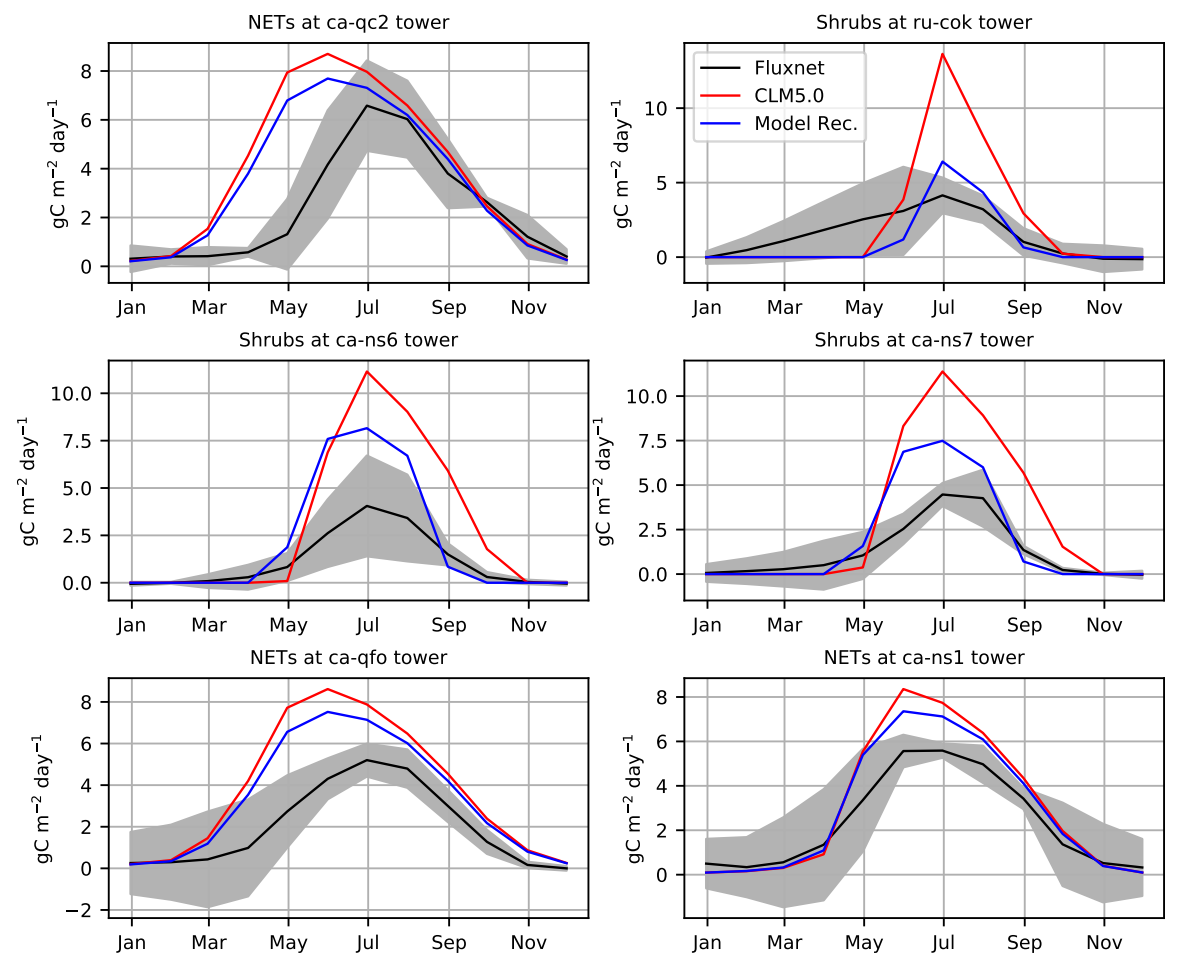

Figure S11. Additional Flux Tower Comparisons for PFTs that were not dominant on the gridcell. 
Needleleaf Evergreen GPP at CA-QC2 with Leuning

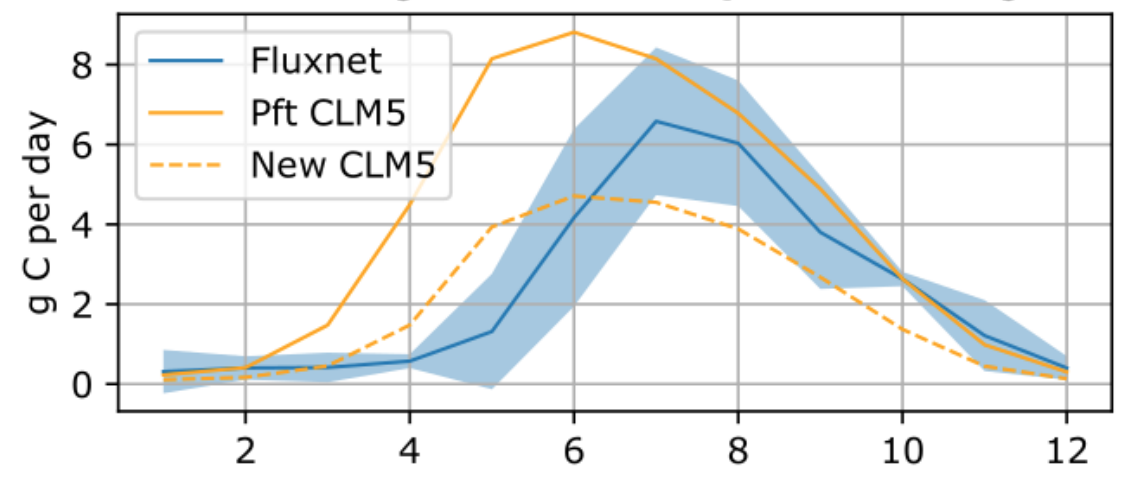

Needleleaf Evergreen NEE at CA-QC2 with Leuning

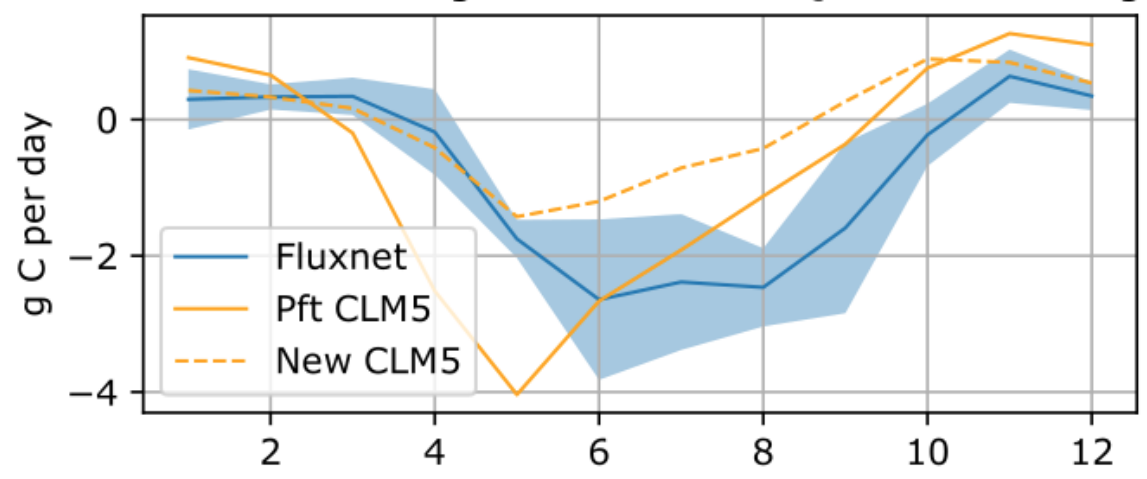

Figure S12. Analysis of GPP and NEE at CA-QC2 (needleleaf evergreen trees) with Leuning in place of Kattge and Knorr. 

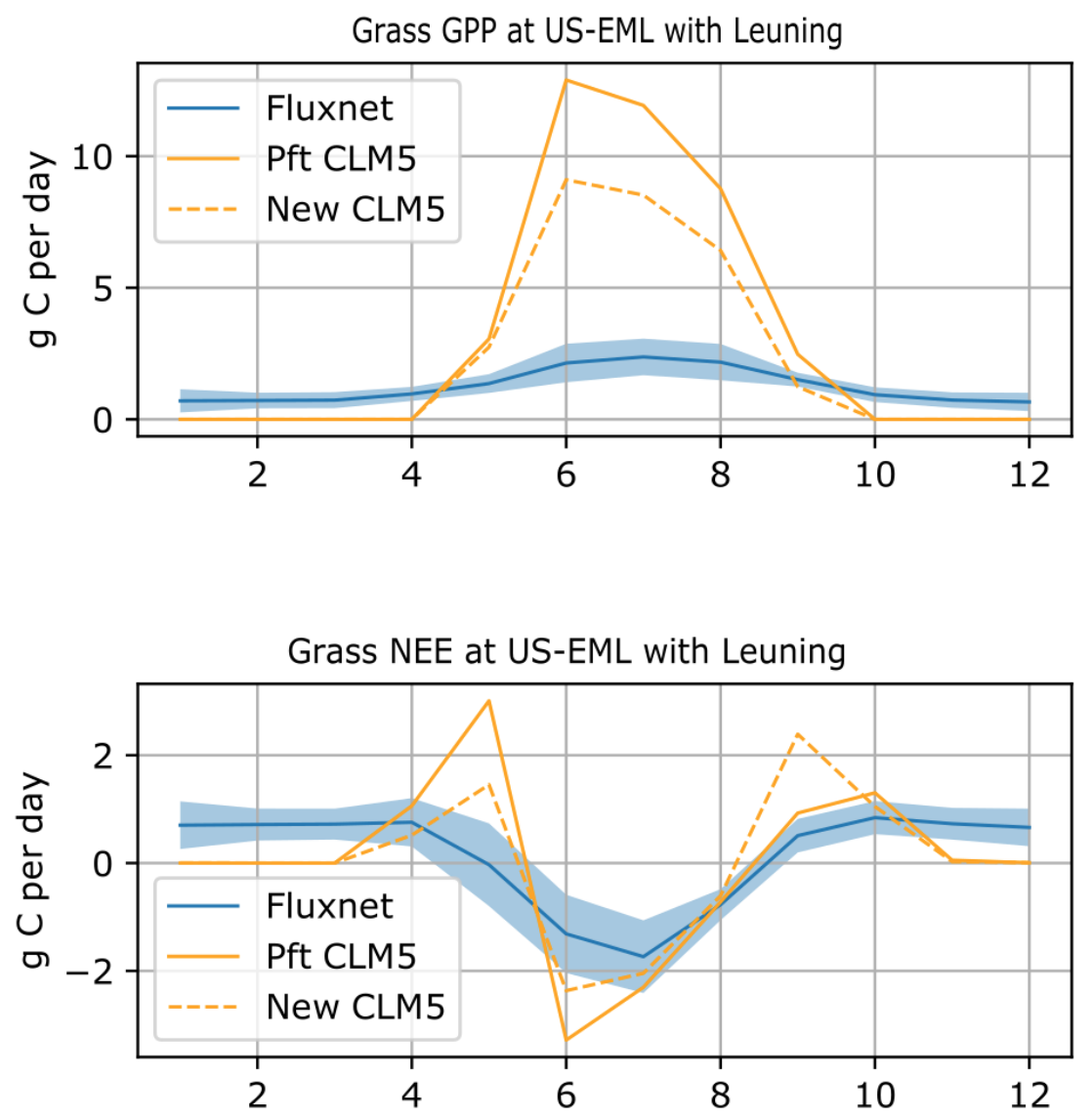

Figure S13. Analysis of GPP and NEE at US-EML (grasses) with Leuning in place of Kattge and Knorr. 

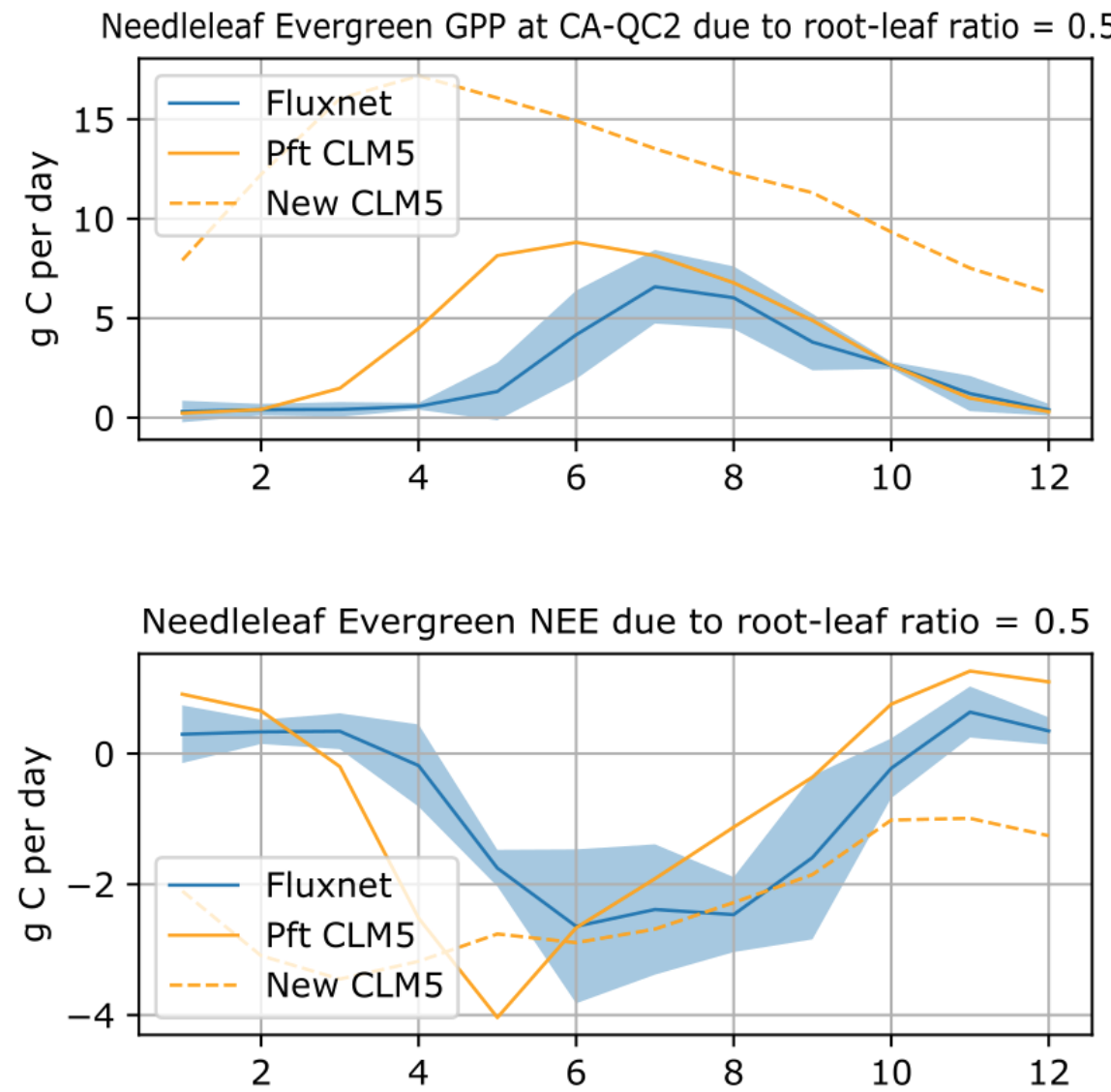

Figure S14. Analysis of GPP and NEE at CA-QC2 needleleaf evergreen trees with lowered root-leaf ratio. 


\section{References}

40 Amiro, B.: FLUXNET2015 CA-SF1 Saskatchewan-Western Boreal, forest burned in 1977, Tech. rep., FluxNet; University of Manitoba, 2016.

Aurela, M.: FLUXNET2015 RU-Tks Tiksi, Tech. rep., FluxNet; Finnish Meteorological Institute-Helsinki, 2016.

Aurela, M., Tuovinen, J.-P., Hatakka, J., Lohila, A., Mäkelä, T., Rainne, J., and Lauria, T.: FLUXNET2015 FI-Sod Sodankyla, Tech. rep., FluxNet; Finnish Meteorological Institute, 2016.

45 Belshe, E., Schuur, E., Bolker, B., and Bracho, R.: Incorporating spatial heterogeneity created by permafrost thaw into a landscape carbon estimate, Journal of Geophysical Research: Biogeosciences, 117, 2012.

Black, T. A.: FLUXNET2015 CA-Obs Saskatchewan-Western Boreal, Mature Black Spruce, Tech. rep., FluxNet; The University of British Columbia, 2016.

Dolman, H., van der Molen, M., Parmentier, F.-J., Marchesini, L. B., Dean, J., van Huissteden, K., and Maximov, T.: FLUXNET2015 RU-Cok Chokurdakh, Tech. rep., FluxNet; Vrije Universiteit Amsterdam, 2016.

Goulden, M.: AmeriFlux CA-NS6 UCI-1989 burn site, Tech. rep., AmeriFlux; University of California-Irvine, $2016 \mathrm{a}$.

Goulden, M.: FLUXNET2015 CA-NS4 UCI-1964 burn site wet, Tech. rep., FluxNet; University of California-Irvine, $2016 \mathrm{~b}$.

Holl, D., Wille, C., Sachs, T., Schreiber, P., Runkle, B. R., Beckebanze, L., Langer, M., Boike, J., Pfeiffer, E.-M., Fedorova, I., et al.: A long-term (2002 to 2017) record of closed-path and open-path eddy covariance CO 2 net ecosystem exchange fluxes from the Siberian 55 Arctic, Earth System Science Data, 11, 221-240, 2019.

Kattge, J. and Knorr, W.: Temperature acclimation in a biochemical model of photosynthesis: a reanalysis of data from 36 species, Plant, cell \& environment, 30, 1176-1190, 2007.

Kutzbach, L., Sachs, T., Boike, J., Wille, C., Schreiber, P., Langer, M., and Pfeiffer, E.-M.: FLUXNET2015 RU-Sam Samoylov, Tech. rep., FluxNet; GFZ German Research Centre for Geosciences, https://doi.org/10.18140/FLX/1440185, 2002-2014.

60 Leuning, R.: Temperature dependence of two parameters in a photosynthesis model, Plant, Cell \& Environment, 25, 1205-1210, 2002.

Margolis, H.: AmeriFlux CA-Qc2 Quebec-1975 Harvested Black Spruce (HBS75), Tech. rep., AmeriFlux; Laval University, 2018.

Margolis, H. A.: FLUXNET2015 CA-Qfo Quebec-Eastern Boreal, Mature Black Spruce, Tech. rep., FluxNet; Université Laval, 2016.

Maximov, T.: FLUXNET2015 RU-SkP Yakutsk Spasskaya Pad larch, Tech. rep., FluxNet; IBPC, Russia, 2016.

McCaughey, H.: FLUXNET2015 CA-Gro Ontario-Groundhog River, Boreal Mixedwood Forest, Tech. rep., FluxNet; Queen's University, 2016.

Oechel, W. C., Laskowski, C. A., Burba, G., Gioli, B., and Kalhori, A. A.: Annual patterns and budget of CO2 flux in an Arctic tussock tundra ecosystem, Journal of Geophysical Research: Biogeosciences, 119, 323-339, 2014. 